\title{
PENERAPAN ALGORITMA K-MEDOIDS CLUSTERING UNTUK PENGELOMPOKKAN PENYEBARAN DIARE DI KOTA MEDAN (STUDI KASUS: KANTOR DINAS KESEHATAN KOTA MEDAN)
}

\author{
Bambang Riyanto \\ Program Studi Teknik Informatika, STMIK Budi Darma, Medan, Indonesia \\ Email : riantobambang@gmail.com
}

\begin{abstract}
Abstrak
Dinas kesehatan bertugas menyuluh dan mendata penderita diare di tiap-tiap daerah, kemudian daerah tersebut akan dievaluasi daerah mana saja yang paling banyak terkena diare. Dan dilakukan pengecekan lansung ke lapangan teryata didapatkan penyebab paling mendasar adalah tentang lingkungan yang kurang bersih seperti parit-parit yang terlalu banyak sampah, sehingga menyebabkan banjir pada saat musim hujan. Dinas kesehatan juga menghibau agar masyarakat untuk selalu menjaga kebersihan lingkungan dan membiasakan masyarkat untuk selalu mencuci tangan dengan sabun pada saat sebelum makan dan setelah melakukan kebersihan dengan hal-hal sederhana seperti ini diharapkan dapat membantu mengurangi penderita diare di kota Medan.K-Medoids Clustering merupakan algoritma clustering yang mirip dengan K-Means. Perbedaan dari kedua algoritma ini yaitu algoritma K-Medoids atau PAM menggunakan objek sebagai perwakilan (medoid) sebagai pusat cluster untuk setiap cluster, sedangkan K-Means menggunakan nilai rata-rata (mean) sebagai pusat cluster.
\end{abstract}

Kata Kunci: Diare, Kantor dinas, Data mining, Algoritma K-Medoids

\begin{abstract}
The health office is in charge of instructing and registering diarrhea sufferers in each region, then the area will be evaluated which areas are most affected by diarrhea. And checking directly into the field revealed that the most basic cause was about the unclean environment such as trenches that were too much garbage, causing floods during the rainy season. The health office also encourages the community to always maintain environmental cleanliness and familiarize people to always wash their hands with soap before eating and after cleaning with simple things like this is expected to help reduce diarrhea sufferers in the city of Medan. K-Medoids Clustering is clustering algorithm which is similar to K-Means. The difference between these two algorithms is the K-Medoids or PAM algorithm uses the object as a representative (medoid) as the center of the cluster for each cluster, while the K-Means uses the mean (mean) as the center of the cluster.
\end{abstract}

Keywords: Diarrhea, Service office, Data mining, K-Medoids Algorithm

\section{PENDAhUluan}

Diare adalah penyakit buang air besar yang sangat encer dan dapat berwarna hijau atau dapat pula bercampur lender darah atau lender aja penyakit ini terjadi dikarenakan banjir dan linkungan yang tercemar, penyakit diare tidak hanya menyerang orang dewasa saja anak-anak juga bisa terkena. Adapun angka kematian yang dirilis UNICEF september 2012 menunjukkan bahwa secara global sekitar 2.000 anak dibawah usia lima tahun meninggal karena penyakit diare[1].Dinas kesehatatan adalah unsur pelaksana pemerintah kota dalam bidang kesehatan yang dipimpin oleh seorang kepala dinas yang berada dibawah kepala daerah melalui sekretaris daerah dan bertanggung jawab melaksanakan urusan pemerintahan dibidang kesehatan yang meliputi kesehatan masyarakat, pencegahan dan pengendalian penyakit, pelayanan dan sumber daya kesehatan, serta tugas pembantu yang diberikan kepada kabupaten.Penyebaran penderita diare yang merata hampir keseluruh kawasan Indonesia salah staunya di kota Medan, luasnya kota medan memungkinkan agak sulit untuk mencari datanya satu persatu sehingga perlu adanya pengelompokkan wilayah penyebaran diare. Dengan mengkelompokkan data penyebaran diare maka akan mudah mencari data-data penyebaran diare di kota Medan.Pada penelitian ini penulis akan mengelompokkan data penyebaran diare di kota Medan menggunakan algoritma k-medoids clustering untuk mempermudah mengelompokkan penyebaran diare di kota Medan. Data mining adalah serangkaian proses untuk mengganti nilai tambah berupa informasi yang selama tidak diketahui secara manual dari suatu basis data dengan menggunakan penggalian pola-pola dari data dengan tujuan untuk manipulasi data menjadi informasi yang lebih berharga. Oleh karena itu penulis membuat suatu sistem yang mampu mengelompokkan penyebaran diare di kota Medan, pada studi kasus Kantor Dinas Kesehatan Kota Medan, sehingga metode ini menghasilkan data yang tepat dan akurat.

\section{TEORITIS}

\subsection{Data Mining}

Penggalian data (bahasa Inggris: data mining) adalah ekstraksi pola yang menarik dari data dalam jumlah besar. Suatu pola dikatakan menarik apabila pola tersebut tidak sepele, implisit, tidak diketahui sebelumnya, dan berguna. Pola yang disajikan haruslah mudah dipahami, berlaku untuk data yang akan diprediksi dengan derajat kepastian tertentu, 
berguna, dan baru. Penggalian data memiliki beberapa nama alternatif, meskipun definisi eksaknya berbeda, seperti KDD (Knowledge Discovery in Database), analisis pola, arkeologi data, pemanenan informasi, dan intelegensia bisnis. Penggalian data diperlukan saat data yang tersedia terlalu banyak (misalnya data yang diperoleh dari sistem basis data perusahaan, e-comerce, data saham, data sensus dan data bioinformatika), tetapi tidak tahu pola apa yang bisa didapatkan. Data mining sangat perlu dilakukan terutama dalam mengelola data yang sangat besar untuk untuk memudahkan aktivitas recording suatu transaksi dan untuk proses data worehousing agar dapat memberikan informasi yang akurat bagi penggunanya alasan utama mengapa data mining sangat menarik perhatian industri informasi dalam beberapa tahun belakangan ini adalah karena tersedianya data dalam jumlah yang sangat besar dan semakin besarnya kebutuhan untuk mengubah data tersebut menjadi informasi dan pengetahuan yang berguna karena sesuai fokus bidang ilmu yaitu melakukan kegiatan mengekstrasi atau menambang pengetahuan dari data yang berukuran/berjumlah besar, informasi inilah yang nantinya sangat berguna untuk pengembangan.

Data mining adalah proses analitik yang dirancang untuk memeriksa sejumlah data yang besar dalam mencari suatu pengetahuan tersembunyi yang berharga dan konsisten [2]. Tujuan dari data mining yaitu mencari trend atau pola yang diinginkan dalam database besar untuk membantu dalam pengambilan keputusan pada waktu yang akan datang.

\subsection{Algoritma K-Medoids Clustering}

Algoritma K-Medoids atau Partitioning Around Medoids (PAM) adalah algoritma clustering yang mirip dengan KMeans. Perbedaan dari kedua algoritma ini yaitu algoritma K-Medoids atau PAM menggunakan objek sebagai perwakilan (medoid) sebagai pusat cluster untuk setiap cluster, sedangkan K-Means menggunakan nilai rata-rata (mean) sebagai pusat cluster [5]. Algoritma K-Medoids memiliki kelebihan untuk mengatasi kelemahan pada pada algoritma K-Means yang sensitive terhadap noise dan outlier, dimana objek dengan nilai yang besar yang memungkinkan menyimpang pada dari distribusi data. Kelebihan lainnya yaitu hasil proses clustering tidak bergantung pada urutan masuk dataset. Langkahlangkah algoritma K-Medoids:

1. Inisialisasi pusat clustersebanyak $\mathrm{k}$ (jumlah cluster)

2. Alokasikan setiap data (objek) ke clusterterdekat menggunakan persamaan

ukuran jarak Euclidian Distance dengan persamaan:

$$
(x, y)=\|x-y\|=\sqrt{ } \sum(x i-y i)^{2} n i=\ldots
$$

3. Pilih secara acak objek pada masing-masing cluster sebagai kandidat medoidbaru

4. Hitung jarak setiap objek yang berada pada masing-masing cluster dengan kandidat medoidbaru.

5. Hitung total simpangan (S)dengan menghitungnilai total distancebaru -total distancelama. Jika $\mathrm{S}<0$, maka tukar objek dengan data cluster untuk membentuk sekumpulan kobjek baru sebagai medoid.

6. Ulangi langkah 3 sampai 5 hingga tidak terjadi perubahan medoid, sehingga didapatkan cluster beserta anggota cluster masing-masing.

Clustering merupakan suatu proses pengelompokkan record, observasi, atau mengelompokkan kelas yang memiliki kesamaan objek [5].

\subsection{Diare}

Diare merupakan gangguan Buang Air Besar (BAB) ditandai dengan BAB lebih dari 3 kali sehari dengan kosisten tinja cair, dapat disertai dengan darah. Penyakit diare masih diperkirakan lebih dari 10 juta anak berusia kurang dari 5 tahun meninggal setiap tahunnya di dunia dimana sekitar $20 \%$ meninggal karena infeksi diare.Kejadian diare dapat terjadi di seluruh dunia dan menyebabkan $4 \%$ dari semua kematatian dan 5\% dari kehilangan kesehatan menyebabkan kecacatan.

Diare tetap menjadi penyebab utama kematian pada anak-anak di bawah usia 5 tahun di Negara-negara Sub-Sahara di Afrika. Faktor resiko untuk diare akut bervariasi berdasarkan konteks dan memiliki implikasi penting untuk mengurangai beban penyakit. Diare juga merupakan penyakit yang bertanggung jawab untuk sekitar seperempat dari 130.000 kematian tahunan diantara anak balita, terutama pada musim pancaroba seperti yang terjadi dihampir seluruh kawasan Indonesia.

Gejala diare bervariasi, umumnya meliputi perut kembung atau kram, tinja encer, rasa mulas, atau terkadang mual dan muntah. Penderita dapat mengalami satu atau beberapa gejala sekaligus, tergantung dari penyebab diare.

1. Gejala lainnya yang mungkin juga dapat terjadi adalah:

a. Penurunan berat badan.

b. Tinja berlendir, berdarah, atau mengandung makanan yang belum tercerna.

c. Demam.

d. Sakit kepala.

2. Sedangkan tanda-tanda yang menunjukkan penderita diare mengalami dehidrasi adalah:

a. Pusing.

b. Rasa haus berlebihan. 
c. Urine menjadi sedikit atau berwarna gelap.

d. Mulut dan kulit kering.

e. Lemas.

3. Pada bayi atau anak-anak, dehidrasi juga bisa dikenali dari gejala:

a. Mata, perut, dan pipi yang terlihat cekung.

b. Air mata berkurang saat menangis.

c. Tidak ada urine pada popok selama 3 jam atau lebih.

d. Rewel.

Segera cari pertolongan medis jika Anda memiliki bayi atau anak-anak yang mengalami diare selama lebih dari 24 jam, terutama jika disertai gejala dehidrasi, demam melebihi 39 derajat Celsius, tinja mengandung nanah, atau tinja berwarna hitam.

\section{ANALISA DAN PEMBAHASAN}

\subsection{Analisa Masalah}

Pada sub bab ini akan dibahas analisa data dan analisa metode sebagai penyelesaian permasalahan. Data-data yang diteliti adalah data penduduk yang terkena penyakit diare di kota Medan yang berasal dari basisdata kasus pada Kantor Dinas Kesehatan Kota Medan ketika penulis melakukan observasi.

\subsection{Pengumpulan Data}

Data yang digunakan adalah data yang diambil dari Kantor Dinas Kesehatan Kota Medan dalam mengumpulkan data-data masyarakat yang terkena Diare, pada periode tahun 2018. Sekalipun data format dari Kantor Dinas Kesehatan Kota Medan susah untuk dibaca dan dipahami akan tetapi peneliti berusaha untuk mengelompokan dan mengambil data yang sesuai dengan kebutuhan penelitian ini sehingga menghasilkan data yang sesuai dengan tujuan pentelitan, lalu data yang dimaksud yaitu data yang akan diolah.

\subsection{Pembahasan}

Dalam menganalisa kebutuhan dengan menggunakan algoritma K-Medoids Clustering yakni mengelompokkan data berdasarkan nilai rata-rata data yang diteliti dibutuhkan cluster yang merupakan kelompok data dan titik awal cluster. Pada penelitian ini, penulis melakukan 2 cluster. Hal ini merupakan tahap awal untuk menentukan hasil yakni kelompok.

Menentukan titik pusat awal cluster pada metode Data Mining algoritma K-Medoids Clustering adalah dipilih secara random. Adapun titik pusat awal cluster yang dipilih oleh penulis secara random dapat dilihat pada table 1 berikut:

Tabel 1. Data dengan titik awal cluster

\begin{tabular}{cllll}
\hline \multirow{2}{*}{ No } & \multirow{2}{*}{ Wilayah } & \multicolumn{3}{c}{ Usia Terkena Diare } \\
\cline { 2 - 5 } & & $\mathbf{0 , 6}$ bulan s/d 9 tahun & $\mathbf{1 0}$ tahun s/d 19 tahun & $>$ 20 tahun \\
\hline 1 & Bestari & 79 & 58 & 149 \\
2 & Darusalam & 81 & 52 & 199 \\
3 & Glugur kota & 31 & 20 & 94 \\
\hline$\ldots$ & $\ldots$ & $\ldots$ & $\ldots$ & $\ldots$ \\
12 & Belawan & 1122 & 366 & 297 \\
$\ldots$ & $\ldots$ & $\ldots$ & $\ldots$ & $\ldots$ \\
20 & Medan area Selatan & 450 & 433 & 428 \\
\hline
\end{tabular}

Dari table 4.2 tersebut, dapat diambil kesimpulan masing-masing titik awal Cluster berdasarkan urutan yang akan dilakukan penulis yakni kelompok wilayah yang terkena penyakit diare dan kelompok wilayah yang tidak banyak terkena penyakit diare adalah sebagai berikut:

1. Pusat Cluster 1: Data ke-2 dengan 0,6 s/d 9 tahun=81, $10 \mathrm{~s} / \mathrm{d} 19$ tahun $=52$ dan $>20$ tahun $=199$

2. Pusat Cluster 2: Data ke-2 dengan 0,6 s/d 9 tahun=1122, $10 \mathrm{~s} / \mathrm{d} 19$ tahun $=366$ dan $>20$ tahun $=297$

Menghitung Jarak Data ke Pusat Cluster

Pada algoritma K-Medoids Clustering, menghitung jarak setiap data ke pusat cluster adalah bertujuan untuk menentukan titik pusat cluster yang baru menggunakan rumus Euclidian Distancesebagai berikut:

$\mathrm{D}(\mathrm{ik}) d(x, y)=\|x-y\|=\sqrt{ } \sum(x i-y i) 2 n i=1 ; 1,2,3, \ldots . n(2)$

Dimana:Cij $\quad=$ Pusat cluster

$$
\mathrm{Ckj} \quad=\text { Data }
$$


Pada tahapan ini, perhitungan jarak setiap data ke titik pusat cluster dilakukan secara perulangan. Dan apabila nilai pusat cluster pada iterasi tersebut sama dengan nilai pusat cluster pada iterasi sebelumnya, perulangan dihentikan karena hasil telah ditemukan. Adapun perhitungan jarak data ke pusat cluster pada masing-masing iterasi adalah sebagai berikut:

1. Iterasi I

Data-1 ke Pusat Cluster I

Data-2 ke Pusat Cluster I

Data-3 ke Pusat Cluster I

$$
\begin{aligned}
& =(79-81)+(58-52)+(149-199)=-46 \\
& =(81-81)+(52-52)+(199-199)=0 \\
& =(31-81)+(20-52)+(94-199)=-187 \\
& =(\ldots-\ldots)+(\ldots-\ldots)+(\ldots-\ldots)=\ldots \\
& =(1122-81)+(366-52)+(297-199)=1453 \\
& =(\ldots-\ldots)+(\ldots-\ldots)+(\ldots-\ldots)=\ldots \\
& =(450-81)+(433-52)+(428-199)=979 \\
& =(79-1122)+(58-366)+(149-297)=-1499 \\
& =(81-1122)+(52-366)+(199-297)=-1453 \\
& =(31-1122)+(20-20)+(94-297)=-1640 \\
& =(\ldots-\ldots)+(\ldots-\ldots)+(\ldots-\ldots)=\ldots \\
& =(1122-1122)+(366-366)+(297-297)=0 \\
& =(\ldots-\ldots)+(\ldots-\ldots)+(\ldots-\ldots)=\ldots \\
& =(450-1122)+(433-366)+(428-297)=-474
\end{aligned}
$$

\begin{tabular}{|c|c|c|c|c|}
\hline \multirow{2}{*}{ Data ke- } & \multirow{2}{*}{ Satwil } & \multicolumn{2}{|c|}{ Jarak Ke Centroid } & \multirow{2}{*}{ Cluster } \\
\hline & & $\mathrm{C} 0$ & $C 1$ & \\
\hline 1 & Bestari & 0 & 0 & $\mathrm{C} 0$ \\
\hline 2 & Darusalam & 0 & 0 & $\mathrm{CO}$ \\
\hline 3 & Glugur kota & 0 & 0 & $\mathrm{C} 0$ \\
\hline$\ldots$ & . & $\cdots$ & $\cdots$ & \\
\hline 12 & Belawan & 1 & 0 & $\mathrm{C} 1$ \\
\hline$n^{\cdots}$ & $\cdots$ & $\cdots$ & 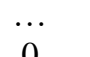 & ${ }^{\cdots}$ \\
\hline 20 & Medan area Selatan & 1 & 0 & C1 \\
\hline
\end{tabular}$$
\text { ...-... ke ... ... }
$$

Data-20 ke Pusat Cluster I

Data-20 ke Pusat Cluster II

Hasil perhitungan menggunakan Euclidian Distance pada iterasi I tersebut diatas dapat dilihat pada table 2 berikut:

Tabel 2. Hasil Iterasi I

\begin{tabular}{llll}
\hline \multirow{2}{*}{ Data ke- } & \multicolumn{1}{c}{ Satwil } & \multicolumn{2}{c}{ Jarak Ke Centroid } \\
\cline { 3 - 4 } & & C0 & C1 \\
\hline 1 & Bestari & -46 & -1499 \\
2 & Darusalam & 0 & -1453 \\
3 & Glugur kota & -187 & -1640 \\
$\ldots$ & $\ldots$ & $\ldots$ & $\ldots$ \\
12 & Belawan & 1453 & 0 \\
$\ldots$ & $\ldots$ & $\ldots$ & $\ldots$ \\
20 & Medan area Selatan & 979 & -474 \\
\hline
\end{tabular}

Tahap selanjutnya adalah menentukan jarak terpendek data terhadap pusat cluster awal yang dipilih secara random sebelumnya. Menentukan jarak terpendek dengan pusat cluster data dapat menggunakan rumus MIN (Cij; Ckj). Adapun hasil penentuan jarak terpendek terhadap pusat cluster yang telah ditabulasikan dapat dilihat pada table 3 berikut:

Tabel 3. Tabulasi Binner Jarak Terdekat Data terhadap Cluster

Berdasarkan nilai minimum yang telah ditentukan menggunakan rumus dan hasil terlihat pada table 4.4 tersebut di atas, maka diperoleh hasil pengelompokan seperti terlihat pada table 4 . berikut

Tabel 4. Hasil Pengelompokan

\begin{tabular}{lll}
\hline Kelompok (Cluster) & Anggota Cluster & Jumlah Anggota \\
\hline 0 & $\{1,2,3,4,7,17\}$ & 6 \\
1 & $\{5,6,8,9,10,11,12,13,14,15,16,18,19,20\}$ & 14 \\
\hline
\end{tabular}


Sehingga didapatkan total Cost $=(-46)+0+(-187)+(-110)+(24)+55+151+237+97+107+(-354)+0+(-$ $1216)+(-1145)+(-1377)+(-943)+1694+$

$(-221)+(-1312)+(-474)$

$=-5068$

Tahapan selanjutnya adalah menentukan titik pusat cluster baru yakni dengan mencari rata-rata semua anggota cluster dengan cara menjumlahkan seluruh value anggota cluster dibagi jumlah anggota. Adapun titik pusat cluster baru beserta value setiap variable adalah sebagai berikut:

$$
\begin{aligned}
\mathrm{C}_{0}(\mathrm{X} 1) & =\frac{\text { Value }(1+2+3+4+7)}{5} \\
= & \frac{(79+81+31+95+102)}{5} \\
= & \frac{388}{5}=306,4 \\
\mathrm{C}_{0}(\mathrm{X} 2) & =\frac{\text { Value }(1+2+3+4+7)}{5} \\
= & \frac{(58+52+20+55+43)}{5} \\
= & \frac{228}{5}=193,6 \\
\mathrm{C}_{0}(\mathrm{X} 3) & =\frac{\text { Value }(1+2+3+4+7)}{5} \\
= & \frac{(149+199++94+163)}{5} \\
= & \frac{677}{5}=54,6 \\
\mathrm{C}_{1}(\mathrm{X} 1) & =\frac{\text { Value }(5+6+8+9+10+11+12+13+14+15+16+17+18+19+20)}{15} \\
= & \frac{(119+129+170+164+216+511+1122+170+262+188+373+1377+403+150+450)}{5} \\
= & \frac{5556}{15}=1111,2 \\
= & \frac{3978}{15}=795,6 \\
\mathrm{C}_{1}(\mathrm{X} 3) & =\frac{\text { Value }(5+6+8+9+10+11+12+13+14+15+16+17+18+19+20)}{15} \\
\mathrm{C}_{1}(\mathrm{X} 2) & =\frac{(50+105+73+63+47+555+366+73+194+74+206+471+269+128+433)}{15} \\
= & \frac{2952}{15}=590,4 \\
&
\end{aligned}
$$

Berdasarkan proses perhitungan di atas, maka diperoleh centroid baru sebagai tolak ukur pada iterasi selanjutnya dengan nilai sebagai berikut:

$\mathrm{C}_{0}=[306 ; 194 ; 547]$

$\mathrm{C}_{1}=[1111 ; 590 ; 796]$

2. Iterasi 2

Data-1 ke Pusat Cluster I

Data-2 ke Pusat Cluster I

Data-3 ke Pusat Cluster I

...-... ke ... ...

Data-12 ke Pusat Cluster I

...... ke ... ...

Data-20 ke Pusat Cluster I

Data-1 ke Pusat Cluster II

Data-2 ke Pusat Cluster II

Data-3 ke Pusat Cluster II

...-... ke ... ...

Data-12 ke Pusat Cluster II

...-... ke ......

$$
\begin{aligned}
& =(79-306)+(58-194)+(149-547)=-761 \\
& =(81-306)+(52-194)+(199-547)=-715 \\
& =(31-306)+(20-194)+(94-547)=-902 \\
& =(\ldots-\ldots)+(\ldots-\ldots)+(\ldots-\ldots)=\ldots \\
& =(1122-306)+(366-194)+(297-547)=738 \\
& =(\ldots-\ldots)+(\ldots-\ldots)+(\ldots-\ldots)=\ldots \\
& =(450-306)+(433-194)+(428-547)=264 \\
& =(79-1111)+(58-590)+(149-796)=-1712 \\
& =(81-1111)+(52-590)+(199-796)=-2165 \\
& =(31-1111)+(20-366)+(94-297)=-2352 \\
& =(\ldots-\ldots)+(\ldots-\ldots)+(\ldots-\ldots)=\ldots \\
& =(1122-1111)+(590-366)+(297-796)=-712 \\
& =(\ldots-\ldots)+(\ldots-\ldots)+(\ldots-\ldots)=\ldots
\end{aligned}
$$


Data-20 ke Pusat Cluster II

$=(450-1111)+(433-590)+(428-796)=-1186$

Hasil perhitungan menggunakan Euclidian Distance pada iterasi I tersebut diatas dapat dilihat pada table 5 berikut:

Tabel 5. Hasil Iterasi II

\begin{tabular}{llll}
\hline \multirow{2}{*}{ Data ke- } & \multirow{2}{*}{ Satwil } & \multicolumn{2}{c}{ Jarak Ke Centroid } \\
\cline { 3 - 4 } & & C0 & C1 \\
\hline 1 & Bestari & -761 & -1712 \\
2 & Darusalam & -715 & -2165 \\
3 & Glugur kota & -902 & -2352 \\
$\ldots$ & $\ldots$ & $\ldots$ & $\ldots$ \\
12 & Belawan & 738 & -712 \\
$\ldots$ & $\ldots$ & $\ldots$ & $\ldots$ \\
20 & Medan area Selatan & 264 & -1186 \\
\hline
\end{tabular}

Adapun hasil penentuan jarak terpendek terhadap pusat cluster yang telah ditabulasikan ke dalam binner dapat dilihat pada table 6 . berikut:

Tabel 6. Tabulasi Binner Jarak Terdekat Data terhadap Cluster Baru

\begin{tabular}{lllll}
\hline \multirow{2}{*}{ Daka ke- } & \multicolumn{1}{c}{ Satwil } & \multicolumn{2}{c}{ Jarak Ke Centroid } & \multirow{2}{*}{ Cluster } \\
\cline { 3 - 4 } & & C0 & $C 1$ & \\
\hline 1 & Bestari & 0 & 0 & $\mathrm{C} 1$ \\
2 & Darusalam & 0 & 0 & $\mathrm{C} 0$ \\
3 & Glugur kota & 0 & 0 & $\mathrm{C} 0$ \\
$\ldots$ & $\ldots$ & $\ldots$ & $\ldots$ & $\ldots$ \\
12 & Belawan & 1 & 0 & $\mathrm{C} 1$ \\
$\ldots$ & $\ldots$ & $\ldots$ & $\ldots$ & $\ldots$ \\
20 & Medan area Selatan & 1 & 0 & $\mathrm{C} 1$ \\
\hline
\end{tabular}

Berdasarkan nilai minimum yang telah ditentukan menggunakan rumus dan hasil terlihat pada table 4.4 tersebut di atas, maka diperoleh hasil pengelompokan seperti terlihat pada table 7. berikut

Tabel 7. Hasil Pengelompokan

\begin{tabular}{lll}
\hline Kelompok (Cluster) & Anggota Cluster & Jumlah Anggota \\
\hline 0 & $\{1,2,3,4,5,6,7,8,9,10,13,14,15,16,19\}$ & 15 \\
1 & $\{11,12,17,18,20\}$ & 5 \\
\hline
\end{tabular}

Sehingga didapatkan total Cost $=(-761)+(-715)+(-902)+(-825)+(-660)+(-564)+(-739)+(478)+(-618)$

Total cost baru $=(-6555)>(-5068)$

$$
+(-608)(-478)+(-407)+(-639)+(-205)+(-574)+384+738+979+517=-6555
$$

Jika nilai cost baru lebih besar dibandingkan dengan cost lama maka hentikan perhitungan. Maka oleh karena itu, pencarian iterasi dihentikan dan hasil telah ditemukan. Dimana hasil dari pada pengelompokan dapat dilihat pada table 4.5, yaitu C1 adalah kelompok wilayah yang ter mkena banyak penyakit diare, yakni Amplas: 1.431, Belawan: 1.785, Medan deli: 2.026, Medan Johor: 1.564 dan Medan area Selatan: 1.311. Dengan dilakukannya perhitungan pengelompokkan penyebaran diare secara cluster menggunakan algoritma $k$-medoids kita lebih mudah melihat daerah mana saja yang paling banyak terkena penyakit diare.

\section{KESIMPULAN} berikut:

Dengan adanya sistem aplikasi pengelompokkan diare di kota Medan penulis dapat mengambil kesimpulan sebagai

1. Sistem yang digunakan dapat mempermudah pekerjaan dinas kesehatan untuk menentukan wilayah mana saja yang paling banyak terkena diare.

2. Cluster pertama atau C0 merupakan daerah yang tidak terlalu di fokuskan dikarenakan wilayahnya yang tidak terlalu banyak terkena penyakit diare.

3. Cluster kedua atau $\mathrm{C} 1$ merupakan daerah-daerah yang harus menjadi perhatian pemerintah dikarenakan daerah-daerah tersebut menjadi pusat penyebaran diare yang paling banyak di kota Medan. 


\section{REFERENCES}

[1] Fina Nasari. 2016.Penyakit Diare. Andyanastri festy, 2012. Semarang

[2] Florin G. 2011.Data Mining.GrahaIlmu 2011.Yogyakarta

[3] Dyang Falila Pramesti.2017. Proses Data Mining Dalam Penemuan Pengetahuan Database . junaedi, Hartanto 2011. Yogyakarta

[4] Mustalim. 20015. Definisi Data Mining Astuti Fajar. Yogyakarta

[5] PurbaYugi Trianto.2005 Arsitektur Data Mining Hermawan.Yogyakarta

[6] Kaur. 2004 Algoritma K-Medoids Dheerendra. 2014. Yogyakarta

[7] Dinas Kesehatan 2006 Diare

[8] Edi Susanto, 2019 Aplikasi RapidMiner Yudi 2009. Jakarta

[9] Adi Kusrianto, 2010 Tampilan Microsoft excel 